\title{
M-PESA: A Socio-Economic Assemblage in Rural Kenya
}

\author{
LEAH JEROP KOMEN, Daystar University, Kenya
}

\begin{abstract}
The role of information communication technologies in development is contested between those who view it as facilitating broad based human development (Waverman et al., 2005; Jack, Suri and Townsend 2010) and those that view it as counterproductive (Donner 2008, Castel et al 2007). Mobile telephony, in particular, is seen as the most techno-social transformation to occur. For instance, at a macro level, Waverman et al. (2005) note that 'mobile telephony has a positive and significant impact on economic growth and this impact may be twice as large in developing countries'. Kenya's M-PESA is a case in point.

This paper looks at M-PESA as a site of inclusion and exclusion, focusing on two elements: emerging accounts of M-PESA usage, and security on money transfers. The paper presents M-PESA as a social assemblage by adopting DeLanda's (2006) assemblage theory, which opens up macro and micro dichotomies. Data obtained from ethnographic interviews shows that although M-PESA is meeting some needs, it also has deterministic tendencies, such as power and gender hierarchy distributions, though complex in nature. The paper has studied mobile money as a socio-economic assemblage that shows the dynamics of social change not as given, but as constantly forming and reforming.
\end{abstract}

\section{KEYWORDS}

Assemblage, development, M-PESA, security concerns.

\section{Introduction}

'M-Pesa is the world's game changer in mobile money transfers'. (Michael Joseph, Vodafone's director of global mobile money, interview, 2012)

M-PESA was developed by the mobile phone operator, Vodafone, and launched commercially by its Kenyan affiliate, Safaricom, in March 2007. M-PESA ("M" for mobile and "PESA" for money in Swahili) is an electronic payment and store of value system that is accessible through mobile phones (Mas and Radcliffe 2010). To access the service, a customer must first register at an authorised M-PESA retail outlet. The process is free and only requires the customer's name, government ID number, date of birth, occupation and mobile phone number (Mas and Radcliffe 2010). If the customer has an older SIM card, it is swapped for one that supports M-PESA, but their phone number remains the same. 
The customer chooses a secret personal identification number (PIN) and is then assigned an individual electronic money account that is linked to their phone number and accessible through a SIM card-resident application on the mobile phone. Customers can deposit and withdraw cash to/from their accounts by exchanging cash for electronic value at a network of retail stores (often referred to as agents). Once customers have money in their accounts, they can use their phones to transfer funds to other M-PESA users and even to non-registered users, pay bills, and purchase mobile airtime credit or save the money for future use, hence using their mobile phones as banks. The user's PIN is usually a 4 digit secret code used to access one's M-PESA account and transact business. This makes M-PESA considerably 'safe' since only the owner of the mobile phone or one with a registered M-PESA line can access their own money; that is, unless they reveal the secret code to another mobile phone owner. A loss of a mobile phone or subscriber identification module (SIM) card does not affect the money saved on M-PESA accounts.

\section{Mobile money and social transformations}

The influence of mobile money for social transformations can be approached from several standpoints. There are those who believe that mobile technology has the power to transform everyday life by influencing how we interact, how we do business and the like. These are the technological determinists (Waverman et al 2005; Rheingold 2002, Meyrowitz 1985 among others). And yet others from a social constructionist perspective argue that the agency in fact determines the technology (McKenzie and Wajcman 1999; Misa 1994, Jensen 2007). Here privilege is accorded to the user of technology in determining changes in technology.

Another standpoint is the uses and domestication of technology, where rather than view technology and social changes from causal points of view, this stand looks at technology and users as having interrelationships, constantly interacting with the user's ever evolving needs to address present needs and emerging ones (du Gay et al. 2007, Ling 2004, 2007; Donner 2008, Donner and Tellez 2008, Wallis 2013). The proponents of domestication of technology envisaged a technology that moves from the wild (being out there) to find its way to the household (du Gay et al. 1997). Early studies looked at stationery technologies that were positioned within the household such as television (Morley 1986), the video cassette recorder (Gray 2003) and the like. Mobile telephony, on the other hand, does not quite fit into these categories due to its mobility and the capacity to present both the private and public spaces at once, making the distinction between public and private spaces, here or there, blurred.

Assemblage theory is an approach to systems analysis that explains fluidity, exchangeability and multiple functionalities of components making up a whole. These parts that form a whole (assemblage) can be removed to form other assemblages in the process called relations of exteriority. Originally, the theory was conceived by Félix Guattari and Gilles Deleuze, who use the analogy of a warrior, weapon and horse to explain that for there to be a meaningful relationship all these components that serve to deliver a win or loss in a battle must each be interacting with each other. In other words, assemblages are not designed to only do one thing, they have multiple functionalities. Assemblage theory was developed more for social ontology by Manuel DeLanda (2006). DeLanda further singles out key tenets of assemblage theory, including: relations of exteriority versus relations of interiority, processes of territorialisation and re-territorialisations, material and expressive characteristics of components, as well as the macro and micro bridges. Some of the necessary tools of assemblage theory, include: roles that components parts play in an assemblage, some of 
which are material (concrete) and others expressive (virtual); the processes in which an assemblage identity is shaped by the nature of the boundaries created by the ongoing interaction of parts and wholes and resulting in territorialisation (stable), de-territorialisation (unstable) and, in some cases, further re-territorialisation due to the nature of constant dynamic interactions. The other tenet is emergence theory, which posits that as components interact they exhibit properties that give rise to spaces of possibilities, the idea that certain tendencies can be manifested and capacities exercised as components interact bringing to the fore what could otherwise be hidden (DeLanda 2011). Assemblage theory helps to navigate this rather complex interrelationship between humans and their mobile telephony.

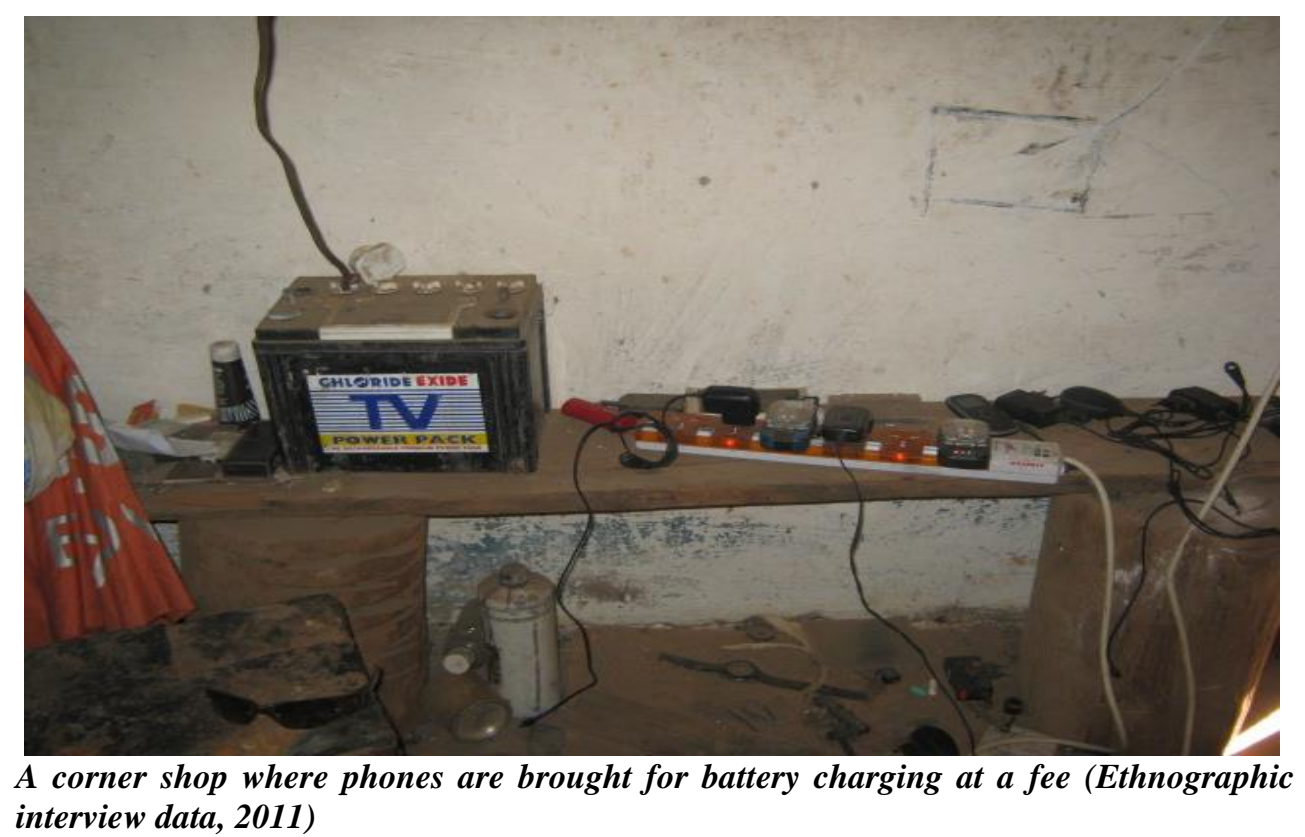

Thus, although a kitchen knife, for instance, can cut, the things to be cut must be cuttable. For that to happen, the knife must be sharpened. It may be solid, but, when exposed to extra heat, it can melt and even turn gaseous under extreme temperatures. M-PESA was originally conceived as a way to transfer money from men working in urban cities to their wives or relatives left back in the countryside. Today the M-PESA can be used by many other users, beyond sending and receiving money, payment of bills and rescue missions, as will be discussed shortly in this paper. In fact, money can even flow from villages to the urban centres.

M-PESA contributes to the ongoing debate on the relationship between technology and society (Maurer 2011). In order to understand the interplay of technology and society, there is a need to go past these micro or macro levels to the actual interplay or interaction that goes on as humans interact with technology. As a social assemblage, M-PESA has both material and expressive roles. The expressive role is about communicating something about oneself or another. Some of the expressive roles include the assumptions that follow M-PESA, such as the touting of mobile phones and services as being appropriate technologies for developing countries (Harvey and Sturgess 2010) due to low cost, ease of use and flexible subscription plans (Andjelkovic 2010; Jack Suri and Townsend 2010). Other expressive roles with MPESA include: mobile network operators (Safaricom), agents' corner shops painted green (for Safaricom) with the operator's logo for easy recognition, M-PESA advertisements that focus 
on free registration; ease of sending money to anyone, anywhere. There are also some undertones such as disgruntled feelings from Kenyan banks feeling that M-PESA is trying to duplicate their services. Then there are new market entrants such as Airtel's mobile money transfer that require no charges for both sending and receiving money.

As observed above, M-PESA comes as a free SIM card encrypted and compatible with most basic phones that are affordable to many individuals, especially those living in rural areas. This compatibility with basic phones and free SIM makes M-PESA able to overcome the material social divide (Hughes and Lonie 2007). The skill challenge seems to be addressed by the SMS response or confirmation text sent when the mobile money transfer is successful. For instance, in the current study, Cheruiyot 53, an illiterate research participant, explains how he has managed to counter the challenge of illiteracy. He explicates as follows:

\section{'You see me, I don't know how to read or write but when an SMS comes from my son, I will ask one of these children to read for me, but then my son also will call to say how much he has sent. So, you see, no one can cheat me of my money.'(Ethnographic data, 2011)}

M-PESA has within it the capacity to include or exclude, allow or disallow persons from accessing and using it. This happens a lot, especially in cases of shared mobile phones, as was the case in Marakwet. M-PESA accounts are shared among close relatives, friends or trusted neighbours. Whereas anyone could be allowed to call or receive a call, M-PESA was slightly different because as one respondent puts it: 'This is money matters!' (Kamau, 39). DeLanda (2006) refers to these processes of allowing persons that are tightly linked as territorialisation, and that of disallowing or excluding others for any reason as deterritorialisation. In Marakwet, M-PESA is territorialising, de-territorialising and, sometimes, re-territorialising on the basis of transactions and persons involved.

M-PESA has the tendency to bring about anxiety and loss. For instance, M-PESA does not have user deposit security per se, such that if one deposited money in their M-PESA account and wishes to send it across to another, a simple mistake of a wrong number would mean that the cash has been lost and the process to recover it is long, should the wrong addressee decide to withdraw the cash and disappear or even discard his or her SIM. Sometimes, such a SIM might not be registered with the company. There is, thus, no guarantee that cash misdirected can be recovered, and this breeds fear, anxiety and uncertainties among users of this otherwise safe software service. To counter this problem, Safaricom has come up with a 15 second verification allowance and a chance to stop it should one notice a wrong destination before the transaction is confirmed. This, however, is only viable to literate customers, and people with clear eyesight; the small font size of the text message can still be a challenge to many.

In summary, to discuss M-PESA as part of a social-economic assemblage means to go past the narrow M-PESA software and user to include government policies, financial institutions and how they have stretched their services through the M-PESA platform to encourage people, to not only open bank accounts, but also to remit their savings to banks using their MPESA accounts, hence bypassing the long queues of customers in many banks. As an assemblage, M-PESA also includes several users irrespective of their gender, existing social structures that prescribe social norms and mores such as honesty, respect for others' hard earned monies and also other services that are needed to make M-PESA rollout possible. A good example of this is to ensure that mobile phones are charged, else having money in one's 
M-PESA account without that individual's phone, or in the case of a shared phone not having enough charge, will mean no access to the said monies, irrespective of the urgency to withdraw them. Some of these charging operators include the corner shops that have battery charging services due to the lack of rural electrification or because of under-developed and under-exploited rural electrification platforms.

\section{Methodology}

The researcher adopted a descriptive and explorative research design, which has been lauded for the ability to describe with an attempt to answer questions such as, 'what is happening' and 'how is it happening' and also explain what already exists without attempting to predict or generalise findings (Dulock 1993). The suitability of the design was in its strength to explain the relationships among M-PESA users, who they are connected to, what else happens in the entire process and how this explains the M-PESA as a socio-economic assemblage. The population was the residents of Sibow village in Marakwet Sub-county of Elgeyo-Marakwet County of the western part of Kenya. A sample was drawn from $10 \%$ of the households on Sibow village, which comprises 100 households. Mugenda and Mugenda, (2008) argue that any population sample size between $10-50 \%$ is appropriate for a study.

The researcher interviewed 10 households in Sibou village and an additional 2 households who were non-adopters of M-PESA just to draw a contrast. To complement the data, 5 focus group discussions were also conducted among perceived homogeneous social groups (women, men and women together, clan leaders, teenage girls and boys, respectively) so as to get a general understanding of the use and consumption of mobile telephony against the background of household and family.

Participants were implored by the researcher to give their personal encounters with mobile phones with each individual giving their experiences as they have used the device and were assured of their anonymity. Those who could read and write signed a consent form while those who could not gave a nod and others spoke verbally and their consent recorded in a digital voice recorder.

Verbal consent was the most preferred over the formal signing against a consent form due to a preconceived notion of formal documents being government documentations usually used to obtain consent from participants, with or without participants being involved in matters that affect them.

A total of 25 one-to-one ethnographic interviews were carried out across demographic characteristics of the participants, 5 focus group discussions were also conducted and with the permission of participants and audio-recorded, as well as videotaped; responses were then transcribed and coded accorded to emerging themes, and analysed using the theoretical framework. The researcher also kept observation notes as further triangulation of data collection tools to improve validity and increase data reliability. Questions asked covered largely individual uses of mobile phones in regard to M-PESA, and whether or not among those uses there was an implication for development activities, such as purchase of goods for business or sending money for agricultural inputs, which is the area's main economic stay, and what bills were paid via the M-PESA. 


\section{Findings and Discussions}

An article in The Times newspaper of Britain was captioned as follows: 'Poorest farmers can feed the world with a $\$ 5$ mobile phone.' This headline was a culmination of reports compiled by Vodafone, Accenture and Oxfam. In the article, the writer argues that with sufficient utilisation of the mobile phone for agricultural purposes the world's poorest could solve the impending food crisis by giving vital information directly to farmers in emerging markets in Asia and sub-Saharan Africa. The reports also affirmed the urgency for food security, stating that 'up to two billion people are dependent on smallholder agriculture', and it is in the utilisation of mobile phones for agricultural purposes that this problem will be tackled, all other things being equal. The practicality of how exactly mobile telephony would translate to food security in Sub-Saharan Africa was not articulated in the reports.

The reports cited mobile commerce (m-commerce) as the driving force of agricultural uptake, especially in Africa and India where the lack of high street banking services has meant that a majority of people have never held bank accounts. However, this is debatable and warrants empirical studies. In the current study, for instance, a majority of those who used mobile money provision, be they their own phones or shared, admitted that they hardly send money for saving purposes. Kigen (39) and Chekieny (68) said that their M-PESA money is really for the purpose of purchasing talk time, and sending the same to their relations in case of emergencies like sicknesses or someone needing urgent cash. Upon further probing, the two participants were found to have bank accounts. Another respondent, in a quick counter statement, stated as follows: 'As for me I don't have that much money to live on let alone to save, so I use my M-PESA account really to receive cash from my children, who don't make much too. So I hardly save' (Kiatu, ethnographic data, 2012).

Despite the above statement, M-PESA is widely viewed as a success story to be emulated across Africa and the developing world (Jack, Suri and Sloan 2010). M-PESA has the potential to greatly affect the Kenyan poor on a number of fronts, including savings and increased outcomes. For instance, people are carrying less money around, making physical insecurity rare. Beyond physical security, food security has improved because M-PESA farmers can easily hire extra labour and the time and money saved in travelling to town increases productivity (Plyer et al. 2010). This, however, is challenged in the current study, with the majority of participants acknowledging savings in terms of time, but admitting they would then re-channel the monies to other needs, leaving little room for savings, if any. Recently, many governments in developing economies and agencies are making concerted efforts to extend telecommunications services, especially mobile telephony, to rural areas as an intention to: (a) alleviate poverty (b) encourage economic growth, and (c) overcome or, at least reduce, the digital divide. However, what is absent in this discourse is how exactly they will expedite this. It could be argued that market agenda could be the driving force to get markets for mobile phones companies.

The uptake and use of M-PESA as a bridge between rural non-banking or less-banked folk and the banking urban centres has been described or perceived as transformative. M-PESA lets people make small to bigger financial transactions using SMS technology without having to create bank accounts or having to physically carry cash. As a result, those who were previously excluded from formal financial activities (i.e. saving money, sending money, etc.) that could be made available through operating a bank account can now actively participate in the financial industry. On this premise, M-PESA has been praised as one of the most 
successful business models in developing countries, as it is believed to have 'significantly' contributed to poverty relief, job creation for dealers and sustainable development. But is this the case across Kenya? Is M-PESA the magic bullet needed for development to occur and be sustained in Kenya? Does it exist in itself or is it a part of the ingredients to form the great development story? Does M-PESA foster socio-economic and cultural inclusion, hence development? These questions will be addressed in the following paragraphs.

Among the changes researchers have noted are changes in the nature, pattern and impact of remittances. Morawcyznski and Pickens (2009) observe that M-PESA users sent smaller but more frequent remittances, which resulted in larger remittances being made to rural areas. They also observe that urban migrants using M-PESA visited their rural homes less frequently, potentially weakening the social ties between them and their home communities. However, this claim has been disputed by the responses and experiences of several participants in this study. For instance, Siaban, 54, a civil servant and polygamist married to three wives, all living in different locations within the district, states that since the advent of the mobile phone he gets to talk daily to his wives and children scattered across the valley, hence strengthening the family unit. He perceives having cash readily on M-PESA as enabling him to purchase air-time to talk to his family members in the rural areas. Below is his testimony:

'This is really good because I even get to talk to my shamba boys (farm workers) using the same phone unlike those days without the phone. I would have to go home literally and that would mean not accomplishing much. With around kshs 300 I get to talk to everyone, even my kids know papa will call to find out about their homework. So I find that I am much closer to my family now.'

Researchers have also noted the potential or capacity of M-PESA to affect savings. Morawcyznski and Pickens (2009) observe that users often keep a balance on their M-PESA accounts, thereby using the system as a rudimentary bank account, despite the fact that the system does not provide interest. In addition, Vaughn (2007) notes that some individuals stored money in M-PESA due to safety considerations, especially when travelling across the country. Plyler et al. (2010) argue that M-PESA has enabled small businesses to expand and grow and also increased the circulation of money in those communities. Findings from the above researchers represent M-PESA as a safe haven for many, especially in regard to money saved, since one has to have a PIN to access it. However, the current study suggests that MPESA causes worries, too, especially if someone mistakenly sends money to the wrong person despite the 15 second confirmation text prior to confirmation of the destination.

M-PESA has the property of savings that is dependent on individuals' capacities to make money and save for future use thus affecting economic activity directly, by increasing access to funds, and indirectly, by increasing savings and banking rates. Plyler et al. (2010) argue that M-PESA has promoted the growth rates of small-scale firms in the communities they studied, and that this was largely driven by the increased circulation of money in these communities. However, this remains a wishful thinking as long as people are poor and have no way of making personal savings.

M-PESA has the potential and capacity to influence several groups of the community towards empowerment. For instance women in this ethnographic study felt that because they have access to mobile phones and can use the M-PESA function, they have been liberated from their husbands' control of monitoring who calls them for how long, what time, and, most 
importantly, from denying them access to money sent by their sons and daughters working in the urban cities. Several women in the women cohort shared this view, and emphasised that with M-PESA they can save towards responding to household needs, and even towards development projects, such as rice farming, mangoes and green gram businesses that seem to thrive in the area. The explanation by Chepkieny says it all:

'M-PESA has made us women able to have some control in our hands. Imagine my husband used to be sent cash by our son working in Nairobi [capital city of Kenya]; he would use the money for drinking the local brew and if I ask him for money for food his excuse will always be we don't have money. Even when I confronted him over the said money sent by our son, he would say I had no business over the money that was sent to him. It was then that I discovered I can open an M-PESA account secretly and now I get money sent to me by our son, but my husband has no idea. I have developed our home a lot. I bought the green grams seedlings, paid school fess for our smaller children. Now I have another problem; he thinks someone is giving me money, like suspecting me. Well, it is his problem.'

The above confession by Chepkieny can be multifaceted; on one hand, she is liberated and money can now be channelled to proper use, such as educating the children or engaging in agriculture, such as the sale of green grams; but it is also a source of mistrust, as she explicates her worries in her marital relationship. This is typical of assemblage theory, as earlier stated, where there is no single logic or explanation; it cannot be reduced to components that form it.

Another participant reiterated the issue of empowerment thus:

'Well, as for me, he knows I do get cash from our children; but he demands to control it. Initially, I used to bring the cash, but then as I talked to my fellow women, I realised they too had decided to be clever; so I withdraw money sent me but give him only some of it...I have saved money in my account number and he cannot access it. I keep changing my PIN number (Chepchumba, 53 years old, ethnographic interview data, 2011).

The above quote by Chepchumba shows that M-PESA is a double-edged sword, such that it liberates her to be able to get cash without her husband's knowledge, meaning she can have control over the funds. Yet, at the same time, M-PESA has the tendencies to be used for mischief, too, and on other occasions it curtails the liberty, since Chepchumba has to be extra vigilant to make sure that her husband never gets to know, otherwise she could be in untold trouble.

Money stored or transferred through M-PESA can be used for numerous purposes, such as: to purchase agricultural farm tools and seedlings, purchase goods for small retails shops, and emergency situations like abrupt illness, payment of hospital bills and making religious remittances, purchase food stuff and talk time, and so on. This study established that very few of them used it for such purposes, though. The ability of M-PESA to allow for deposits and withdrawals makes it a versatile tool, however, so that when used it can result in development or underdevelopment. 


\section{M-PESA and micro/macro level discourse}

M-PESA penetration has reached greater heights, sending fright to many banks, which necessitated the introduction of a link between mobile phone operators, users and banks.

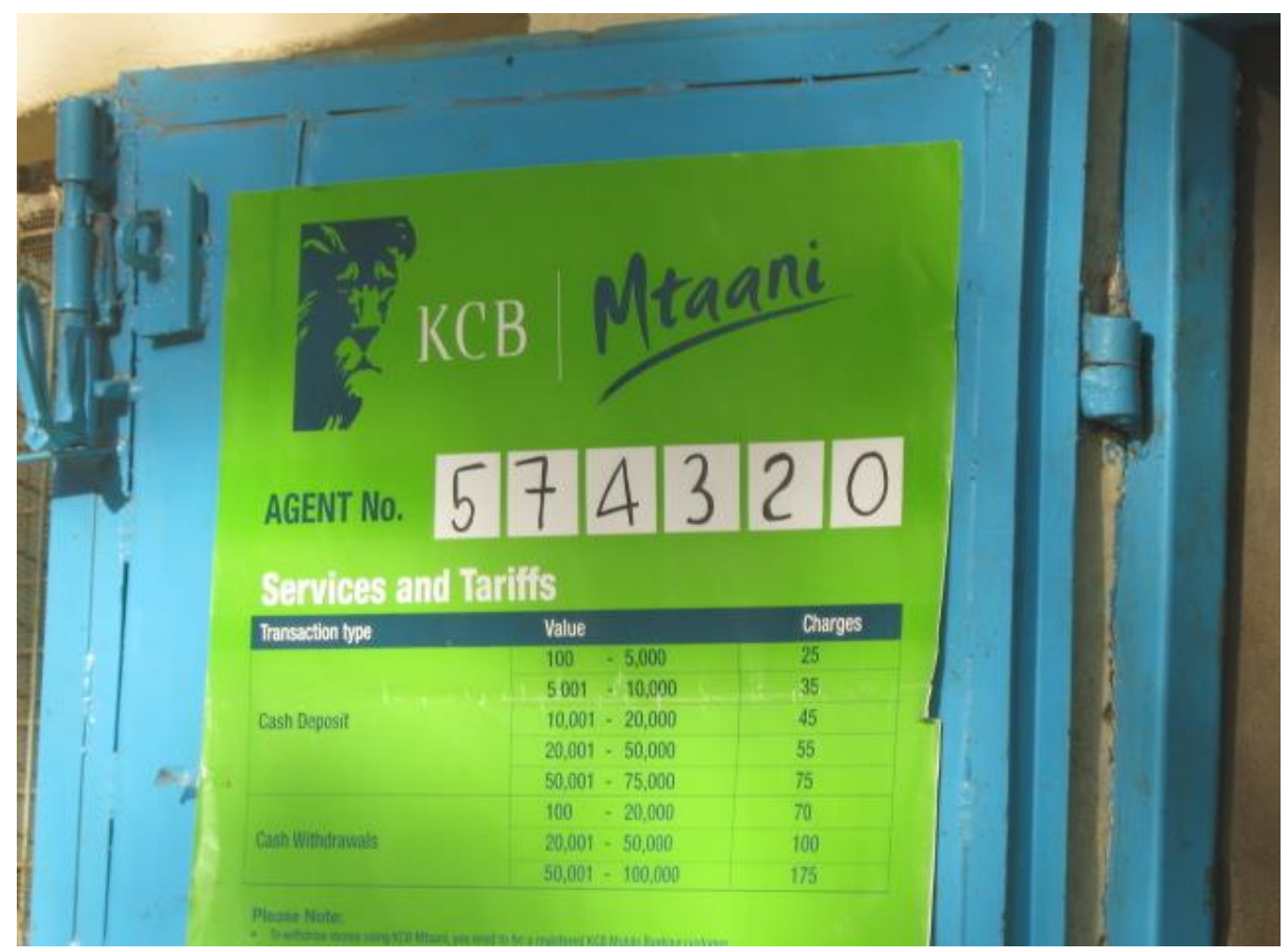

Poster showing link between local bank KCB and an M-PESA agents network (Ethnographic data 2011)

Users with bank accounts are persuaded to remit or deposit money to their bank account using a link from the bank. In other words, M-PESA can link actors, institutions and the processes that occur between micro and macro agencies. As a means to control crime and criminal activities, the government of Kenya required that all mobile phone users be registered and, at the same breath, one of Kenya's service providers, Safaricom, also went to register all of its M-PESA account holders, which now serves as a means of detecting fraudulent and criminal activities. Though Safaricom own the database, should there be an investigation, such data is requested by the government and therefore the surveillance, if you like, is alive to some extent.

Jack and Suri (2009) observe that the nature of M-PESA use could allow users to set up their personal savings accounts, because friends and even relatives would not be able to know the timing or the amount of money stored in these accounts. Additionally, members who are registered users of M-PESA can also pull their monies together and converge them in a group M-PESA account, for various purposes, such as tilling land, transporting their farm produce to the city for sell and the like. For instance, in the current study, members of social groups, such as Chesawach traditional dancers, would send their little earnings to a group M-PESA account, after which they can use it to facilitate their travel whenever a respected member of society, such as the president, area legislator or senator, comes to visit the place, or to engage in rice farming as an entity due to the group savings. (See below, a section of Chesewach traditional dancers displaying their regalia.) 


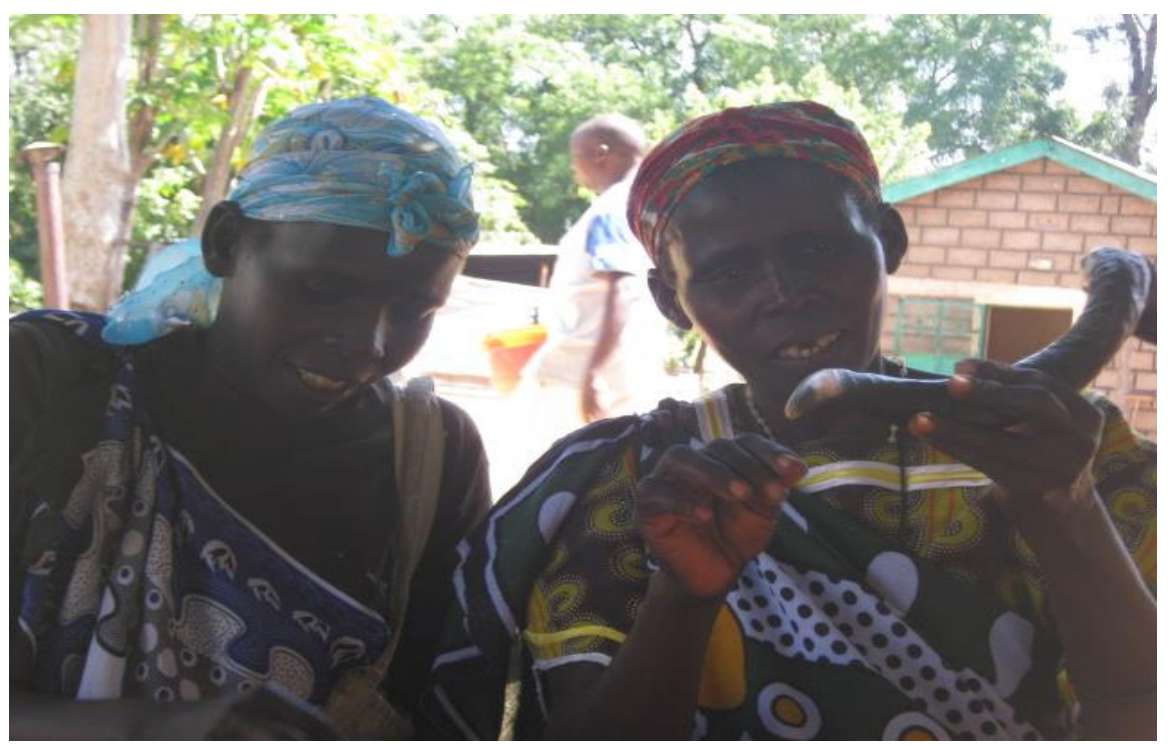

A section of Chesewach traditional dancers (Ethnographic interview data, 2011)

\section{Conclusion}

M-PESA as a social assemblage demonstrates the multi-directional, targeted, flexible and, most importantly, complex relationships between mobile telephony as a communication technology, its users, contexts and series of socio and some economic networks. How money transfers happen is diverse. Some individuals use the monies just to facilitate travel; others use it to avoid travel or skip it; some use it as a control mechanism; yet others see it as a liberator. M-PESA also helps in mapping mobile telephony as an assemblage that involves more actors - from individual users to mobile phone operators, government agencies such as Kenya's communications regulator, the Communication Authority of Kenya (CAK) - and also shared mobile phone use, by showing the connection and association of these parts that together form mobile phone assemblages and money transfer assemblages.

M-PESA also territorialises, in the sense that not everyone is allowed to use a shared phone. Issues of trust and mischief assemblages come into play. Literacy plays a key role in the success story of M-PESA. However, this is not an impediment, as seen in earlier narratives of semi-literate participants, who would ask someone to read out a text for them but still call the one sending the cash through the mobile phone just to double check and guard against mischief by the literate people. In a sense, one can argue that M-PESA equalises social strata given the ability for all to use the service, including the rich, middle income or poor, literate and otherwise, rural or urban dwellers, religious and non-religious, and each gender. However, that does not tell the entire story, because gender differences are also reinforced in mobile money transfer. For instance, in cases where the male takes control of all monies, he utilises or distributes it as he chooses, giving his wife or wives whatever he deems appropriate for her/them. This kind of scenario further impedes development efforts, if the husband spends the said monies on local liquor at the expense of the children's education, agricultural activities, or even the health of the household. Being able to send and receive money through mobile phones is thus both liberating and limiting, and is also a potential source of stress for those who cannot make enough to survive on, let alone share through mobile phones. One can argue further that the introduction and adoption of mobile telephony has encouraged more and more consumption of technology, which could have been the main goal from a business agenda standpoint. 
M-PESA, on the one end, eliminates or limits the discrepancy between the micro and macro by showing the connections and association between the device, mobile phone charging corner shops, users and their contexts, regardless of their socio-economic status or literacy levels. M-PESA can then be said to facilitate development only if it facilitates participation across the household in terms of what the said monies cater for. Is it the paying of education bills so that children are not sent out of school, thus helping to fight or reduce illiteracy levels? Is it the boosting of the household economic status by meeting health needs, such as ill-health, delivering pesticides for crops that are infested, and so on? Or is it about saving, in terms of curtailing unnecessary journeys, among other things? Thus, M-PESA in itself cannot deliver development unless it is a concerted assemblage, as shown above, meaning that monies sent should be channelled towards poverty eradication or, better still, towards socio and economic activities that in the long run promote development.

\section{References}

Andjelkovic, M. (2010) The Future is Mobile. SAIS Review, 30(2), 121-33.

Castells, M., Mireira F., Qui, J., and Araba, S. (2007) Mobile Communication and Society: A Global Perspective. London: MIT Press.

Communication Commission of Kenya (2011) Third quarterly sector statistics report. Nairobi: Communications Commission of Kenya.

DeLanda, M. (2006) A New Philosophy of Society: Assemblage Theory and Social Complexity. London. Continuum.

Donner, J. (2008) Research approaches to mobile use in the developing world: a review of the literature. The Information Society, 24(3): 140-159

Dulock, H. L. (1993) Research Design: descriptive research. Atlanta. Retrieved November, $26^{\text {th }}$, 2015 from http://www.researchgate.net/publication/14948415 Rsearch design descriptive research

Hughes, N., and Lonie, S. (2007) M-PESA: Mobile money for the "unbanked": Turning cell phones into 24 hour tellers in Kenya. Innovations: Technology, Governance, Globalization, 2(1-2): 63-81

Harvey, J., and Sturges, P. (2010) The Cell Phone as appropriate information technology: Evidence from Gambia. Informational Development, 26(2): 148-59.

Jack, W. and Suri, T. (2011) Mobile money: The economics of M-PESA. Washungton DC: NBER. Jensen, R. (2007)

The digital provide; information (technology), market performance and welfare in the South Indian fishers sector. Quarterly journal of Economics, 122(3): 879-924.

Klonner, S., Nolen, P. (2008) Does ICT Benefit the Poor? Evidence from South Africa, University of Essex - mimeo 
Kim, C., Mirsobit, M. and Lee, I. (2010) An empirical examination of factors influencing the intention to use mobile payment. Computers in Human Behavior, 26: 310-322.

Molony, T. (2009) 'Trading Places in Tanzania: Mobility and Marginalization at a time of travel saving technologies.' In M. de Bruijin, F. Nyamnjoh and B. Inge (eds.) Mobile Phones: The new Talking Drums of Everyday Africa. Leiden: Langaa RPCIG.

Morawczynski, O. (2008) Surviving in the Dual system: How M-PESA is fostering urban-to-rural remittances in a Kenyan slum. Proceedings of the Eighth International Conference on Human Choice and Computers (HCC8), Pretoria, South Africa.

Morawczyski, O., and Pickens, M. (2009) Poor people using mobile financial services: Observations on customer usage and impact of M-PESA. Washington, DC: CGAP.

Muto, M. and Yamano, T. (2009) The Impact of Mobile Phone Coverage Expansion on Market Participation: Panel Data Evidence from Uganda. World Development, 37(12): 1887-1896.

Mugenda, O.M, and Mugenda, A.M (2008) Research Methods: Quantitative and Qualitative approaches; Nairobi, Acts press.

Sander, C. (2003) Migrant Remittances to Developing Countries - A Scoping Study: Overview and Introduction to Issues for Pro-Poor Financial Services. London: DfID.

Waverman, L., Meschi, M., and Fuss, M. (2005) The impact of telecoms on economic growth in developing countries. In Africa: The Economic Impact of Mobile Phones, Vodafone Policy Paper Series, Number 3. Newbury, UK.

Leah Jerop Komen is currently a lecturer at Daystar University, Kenya. She has a Masters in Development Communication awarded from Daystar University, and a $\mathrm{PhD}$ from University of East London. Her research interests include: the domestication of communication technologies in Sub-Saharan Africa and how human-technology and context interrelationships form part of social assemblages that intersect with development.

Email: 1komen@daystar.ac.ke or ledavid2002@gmail.com 